\title{
Isolation and Initial Characterization of cDNAs for mRNAs Regulated during Peach Fruit Development
}

\author{
Ann M. Callahan ${ }^{1}$, Peter H. Morgens ${ }^{2}$, and Reuben A. Cohen \\ United States Department of Agriculture, Agricultural Research Service, Appalachian Fruit Research \\ Station, 45 Wiltshire Road, Kearneysville, WV 25430 \\ Additional index words. Prunus persica, softening
}

\begin{abstract}
Peach [ Prunus persica (L.) Batsch] cDNA libraries have been constructed from RNA isolated from immature (30 days after bloom) and ripe fruit. cDNA clones of interest have been identified by differential hybridization among the cDNAs of various peach cultivars or from several stages in fruit development. In addition, several clones were isolated by low stringency hybridizations with oligonucleotides derived from a tomato polygalacturonase cDNA sequence and a cucumber peroxidase amino acid sequence. The pattern of accumulation of the corresponding mRNAs during fruit development was examined by RNA gel-blot analyses in the commercial cultivar Suncrest. Three cDNA clones, pch201, pch307, and pch313, were related to mRNAs that accumulate during the softening stage of fruit development. cDNA clones pchl03, pch205, and pch306 were related to an $m$ RNAs that increase in abundance throughout development, with maximum levels in ripe fruit. cDNA clones pch104 and pch202 were related to mRNAs that exhibit maximum abundance in midfruit development, and clone pch108 was related to mRNA that decreases as the fruit matures. Southern analyses indicated that seven of the cDNAs are represented by only a few genes, while pch104 detects a repetitive family, and pch307 detects a small family of genes. These clones will provide the initial source of genes to manipulate and affect fruit development.
\end{abstract}

Fruit development is a complex biochemical process resulting not only in growth, but also in changes in flavor, aroma, texture, color, and firmness. Peach fruit development is defined by three distinct stages (Chalmers and van den Ende, 1975; Conners, 1918; Lilien-Kipnis and Lavee, 1971; Tukey, 1933). Rapid pericarp cell division and growth occur immediately after bloom in Stage I; embryo development and hardening of the endocarp occur with little size change of the fruit in Stage II; and an increase in fruit size accompanied by the climacteric, final ripening, and softening occur in Stage III (Fig. 1).

The goal of our research is to identify and isolate genes from peach that influence fruit characteristics. These could then be manipulated to positively affect traits of horticultural interest. Our approach is to identify genes of interest in the form of cDNAs using differential hybridization and heterologous gene sequences. The idea behind differential hybridizations is to select a cDNA clone representing an RNA that is more abundant in one stage or cultivar than another. We used commercial-quality vs. low-quality fruit RNAs, firm vs. less firm fruit RNAs, and nonmelting flesh vs. melting flesh fruit RNAs. In this manner, we might identify mRNAs associated with those fruit traits. Heterologous gene sequences are used to isolate peach genes that are the same as genes from other organisms-in this case, tomato polygalacturonase and cucumber peroxidase genes. We chose polygalacturonase as an enzyme that might affect softening, texture, or storage character-

Received for publication 26 Mar. 1992. Accepted forpublication Nov. 1992. We thank Ralph Scorza for guidance and advice as we initiated and carried through this project, Paul Wright for technical help in isolating several of these clones, Diane Wydowski for all her collecting and measuring, John Cordts for assisting in everything from identifying the correct trees to trying a new RNA method, and Jana Pyle and Eve Walton for helping overcome the difficulties in working with peach nucleic acids. We also acknowledge Lenard Gilreath and Bill Horton for their extensive knowledge of peach fruit. and Howard Brooks for his support of this approach to breeding. Mention of a trademark, proprietary product, or vendor does not constitute a guarantee or warranty of the product by the U.S. Dept. of Agriculture and does not imply its approval to the exclusion of other products or vendors that may also be suitable. The cost of publishing this paper was defrayed in part by the payment of page charges. Under postal regulations, this paper therefore must be hereby marked advertisement solely to indicate this fact.

To whom correspondence should be addressed.

Co-senior author. istics of the fruit (Giovannoni et al., 1989: Grierson et al., 198.5; Sheehy et al., 1988: Smith et al., 1988). We chose peroxidase because of its association with pit hardening and flesh browning (Flurkey and Jen. 1978, van Huystee, 1987). The genes identified by differential screens or through heterologous probes would be characterized and could then be manipulated and used to affect fruit traits in a desirable way. One fruit trait that we are interested in affecting is the rate of softening. Slower softening could extend the shelf life of peach fruit and reduce physical damage during handling. By cloning genes involved in softening, we may then be able to affect fruit softening rates through the manipulation (antisense gene insertion) of the expression of those genes (Callahan et al., 1991).

Genes involved in fruit ripening in tomato (Lycopersicon esculentum Mill.) and avocado (Persea americana Mill.) are being identified through their RNA expression patterns and then isolated and used to elucidate their function and importance (Biggs et al., 1986; Christoffersen et al., 1982, 1984; Grierson et al., 1985; Holdsworth et al., 1987: Lincoln et al., 1987; Piechulla et al., 1985). Specifically, genes encoding enzymes potentially involved in softening of tomato fruit are being manipulated through expression of their antisense RNAs to determine their role in softening (Giovannoni et al., 1989; Hamilton et al., 1990; Schuch et al., 1989; Sheehy et al., 1988; Smith et al., 1988).

We previously described changes in mRNA populations during peach fruit development by in vitro translations (Callahan et al., 1989a). We detected increases in concentration in at least seven polypeptides and decreases in at least four as fruit developed. The concentration of one polypeptide increased and then decreased. All of these changes were in polypeptides that were not detected in leaf or ovule RNA translation products. Here we report the cloning of some cDNAs whose corresponding mRNAs either accumulate or decrease during peach fruit development in the commercial quality cultivar Suncrest. Preliminary results have been presented previously (Callahan et al., 1989b, 1991).

Abbreviations: DAB, days after bloom; SDS. Sodium dodecylsulfate; SSC, saline sodium citrate. 


\section{GROWTH CURVE}

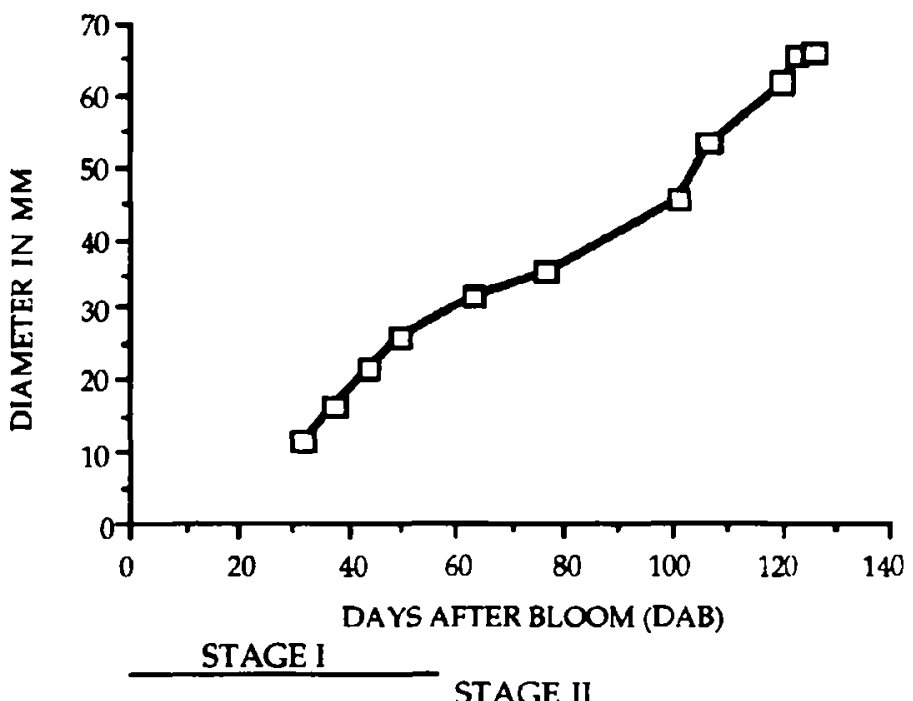

STAGE III

Fig. 1. Change in the diameter of 'Suncrest' fruit over the course of development as measured by the days after bloom (DAB). The fruit were considered ripe at 128 DAB. The stages of development are indicated below the graph and are explained in the text.

\section{Materials and Methods}

Plant material. Fruit of four peach cultivars and one advanced selection were collected for RNA extractions. 'Suncrest' and 'Loring' are commercial-quality cultivars that bear large, yellow, melting-flesh fruit (Brooks and Olmo, 1972). Selection B612615 is an advanced selection with large, white, melting-flesh fruit (Robertson et al., 1989). 'Bailey' has small, poor-quality, white, melting-flesh fruit (Layne, 1982), and 'Suncling' is a commercial canning cultivar that has large, yellow, nonmelting-flesh fruit.

Leaf tissue was collected from new growth in the spring and immediately frozen in liquid nitrogen in the field. Leaf tissue was lyophilized and stored at $-20 \mathrm{C}$ until RNA extraction. Immature leaves, not yet fully expanded, were collected in liquid nitrogen and stored at $-80 \mathrm{C}$ for DNA extractions. Whole fruit were collected <50 days after bloom (DAB), and embryos and ovules were discarded after pit hardening (278 DAB). At least 20 fruit of about the same size were collected each time, frozen in liquid nitrogen in the orchard, and lyophilized together as one batch. Some of this material was milled in a micromill and stored at $-20 \mathrm{C}$. At the same time, 10 fruit were measured and pressure-tested to determine the average size and firmness at that time in development. Fruit for the 1986 developmental series were collected starting 17 DAB. At 103 $\mathrm{DAB}$ the average firmness of the fruit began to decrease, and the flesh and outer pericarp began to change color. The fruit reached maximum size at 128 DAB.

Peaches ripen and soften nonuniformly, so a second series of fruit was collected in 1988 based only on fruit firmness. This represented a softening series consisting of fruit that had reached mature size and begun to change color. These fruit were sorted into the following four classes according to their resistance to a McCormick (McCormick Fruit Technology, Yakima, Wash.) fruit pressure tester: 4 to $19 \mathrm{~N}, 20$ to $39 \mathrm{~N}, 40$ to $59 \mathrm{~N}$, and 60 to $80 \mathrm{~N}$.

Extraction of nucleic acids. RNA and poly $(\mathrm{A})^{+} \mathrm{RNA}$ were prepared as described previously (Callahan et al., 1989a; Morgens et al., 1990) by extracting at $65 \mathrm{C}$ the lyophilized material with buffer containing proteinase $\mathrm{K}$, followed by two phenol extractions at $65 \mathrm{C}$, followed by extraction at $22 \mathrm{C}$ in 1 phenol : 1 chloroform (v/v) and chloroform. RNA was precipitated in $\mathrm{LiCl}(2$ $\mathrm{M})$, resuspended in $\mathrm{H}_{2} \mathrm{O}$, and subsequently precipitated twice in $70 \%$ ethanol. Genomic DNA was isolated as described by Scorza et al. (1990) using a modified technique and reagents from Oncor (Gaithersburg, Md.). Basically, leaf material was ground in liquid nitrogen and resuspended in a lysis buffer to free nuclei. The nuclei were pelleted and then lysed in the presence of proteinase $K$ and urea. The extract was treated with DNase-free RNase and subsequently extracted with buffer-saturated phenol to remove the protein. The DNA was precipitated with ethanol and resuspended in $\mathrm{H}_{2} \mathrm{O}$.

cDNA library construction. Construction of cDNA libraries was as described by Gubler and Hoffman (1983). with the modification that the double-stranded cDNAs were eluted over NENsorb columns after ligation with EcoRI linkers and digestion with EcoRI, according to the manufacturer's directions (DuPont, Wilmington, Del.). The double-stranded cDNAs were then ligated to EcoRI-digested $\lambda$ Zap vector (Stratagene, La Jolla, Calif.). The presence of a cDNA insert in the vector was determined by the lack of B-galactosidase activity as assayed by clear instead of blue plaques in the presence of X-gal as instructed by Stratagene.

In vitro translations. Wheat germ in vitro translations were performed as described by Callahan et al. (1989a). Ten $\mu \mathrm{g}$ of total RNA was added to each reaction along with $50 \mu \mathrm{ci}$ of [35]-Smethionine at $>1000 \mathrm{Ci} / \mathrm{mmol}$ (New England Nuclear, Boston). Equal amounts of TCA-precipitable radioactivity were loaded and protein separated by sodium dodecyl sulfate (SDS)-polyacrylamide gel electrophoresis (PAGE) as described by Callahan et al. (1989a).

Nucleic acid labeling. cDNA probes used to screen libraries were made by incorporating radioactive[ $\alpha^{32}$ P]-dCTP (New England Nuclear) into the synthesis of first-strand cDNA (Maniatis et al., 1982). Plasmid DNA was labeled by nick translation (Maniatis et al., 1982). or cloned inserts were isolated from plasmid DNA by restriction digestion and labeled using a Random Primer DNA Labeling Kit following the instructions provided by the manufacturer (Bio-Rad, Richmond, Calif.). Oligonucleotides were 5'-end labeled with $\left[\gamma^{32} \mathrm{P}\right]$-ATP (New England Nuclear) in a reaction catalyzed by polynucleotide kinase (Maniatis et al., 1982).

Screening cDNA libraries. Clones of interest were identified by differential plaque hybridization according to Maniatis et al. ( 1982 ) or by plaque hybridization with oligonucleotide probes. For the latter, prehybridization and hybridization conditions were $3 \times$ Denhardt's [ $1 \times$ is $0.02 \%$ Ficoll $(\mathrm{w} / \mathrm{v}), 0.02 \%$ polyvinylpyrrolidone $360(\mathrm{w} / \mathrm{v}), 0.02 \%$ bovine serum albumin $(\mathrm{w} / \mathrm{v})] .8 \times$ saline sodium citrate $(\mathrm{SSC})(1 \times$ is $0.15 \mathrm{M} \mathrm{NaCl}$ and $0.015 \mathrm{~m}$ sodium citrate), $1 \%$ sodium dodecylsulfate (SDS), $50 \mathrm{~mm}$ Tris $\mathrm{pH} 8$, and $100 \mu \mathrm{g} / \mathrm{ml}$ salmon testes DNA at 25C. Final washes were done in $2 \times \mathrm{SSC}$, $0.1 \%$ SDS at $32 \mathrm{C}, 37 \mathrm{C}, 45 \mathrm{C}$, and $52 \mathrm{C}$, with exposures to film between washes until all the signal was washed off.

Nucleic acid analyses. RNA gel blot analyses were performed using a developmental series of RNAs and a softening series of RNAs from 'Suncrest'. Total RNA samples were fractionated on $1.4 \%$ agarose gels containing $5 \mathrm{~mm}$ methyl mercuric hydroxide (Bailey and Davidson, 1976) and transferred to Nytran membrane (Schleicher and Schuell, Keene, N.H.). The prehybridization and hybridizations were done in $50 \%$ formamide, $3 \times$ Denhardt's, $5 \times$ SSC, $0.1 \%$ SDS, and $50 \mathrm{~mm}$ Tris, at $\mathrm{pH} 7.8$ and 45C. Final wash conditions were $0.1 \times$ SSC, $0.1 \%$ SDS, 60C. Filters were exposed to Kodak XAR-5 X-ray film with two intensifying screens at $-80 \mathrm{C}$ 
for autoradiography. Radioactive bands were cut out and counted in a Packard Tri-Carb 1500 scintillation counter. Sixteen duplicate blots were made from the same samples. They were stained with methylene blue (Herrin and Schmidt, 1988) to confirm evenness of loading and transfer.

DNA was digested with restriction enzymes, fractionated by electrophoresis through a $0.75 \%$ agarose gel, and transferred to a Sureblot membrane (Oncor) using a Probe Tech I apparatus (Oncor). Prehybridization and hybridization conditions for the Southern blots were the same as for the northern experiments except that $6 \times \mathrm{SSC}$ was used. Final washes were in $0.1 \times \mathrm{SSC}$, $0.1 \%$ SDS, at $52 \mathrm{C}$.

Oligonucleotides. A degenerate oligonucleotide sequence, $\mathrm{GANCC} /{ }_{\mathrm{G}} \mathrm{A} \mathrm{A}{ }_{\mathrm{G}}^{\mathrm{T}} \mathrm{GTGTGNGCNCC}$, representing a highly conserved amino acid sequence GAHTFG in plant peroxidase sequences (Morgens et al., 1990) was kindly provided by Ann Abeles and Marilyn Powers (National Cancer Institute, Frederick, Md.). Two oligonucleotides were kindly provided by John Stout (Upjohn, Kalamazoo, Mich.) based on two GC-rich regions of the tomato polygalacturonase cDNA sequence (Grierson et al., 1986). The first begins at base 555 (GGCCACCATACTTGTCCATTGCCATTGATAGTTCCTCCTCCTCC), and the second begins at 1296 (GCACGTAGCCTCTGATGGTTT TCCACTTTCCCCTAC).

\section{Results}

In vitro translation data indicated that during early fruit development, the RNA population changes in the cultivar Reliance (Callahan et al., 1989a). At later stages of fruit development, fewer differences are detected using the one-dimensional gel system. To determine if differences in translatable RNAs could be detected between the high-quality cultivar Suncrest and the rootstock cultivar Bailey, a developmental series of RNAs were translated and the resulting polypeptides resolved by SDS-PAGE (Fig. 2). Several differences were seen, primarily a $47-\mathrm{kDa}$ polypeptide in early-stage 'Suncrest', which is absent or greatly reduced in 'Bailey', and a 31-kDa polypeptide in 87 DAB 'Bailey', which is absent in 'Suncrest'. We used the in vitro translation information as the basis for constructing three cDNA libraries. An early-stage cDNA library was prepared using 'Suncrest' RNA from fruit picked $30 \mathrm{DAB}$. The library contained 64,500 primary clones, of which $25 \%$ contained inserts. A ripening stage library was constructed from B612615 RNA isolated from ripe fruit 140 DAB, which was the time when the average fruit size was the largest. The library consisted of 210,000 primary clones, of which $88 \%$ contained peach cDNA inserts. This library represented mature-sized fruit, but the firmness of the fruit varied. A third cDNA library, representing the softest stage of ripe fruit, was constructed from 'Loring' RNA isolated from fruit that was between 4 and $19 \mathrm{~N}$ firmness. This library contained 98,000 primary clones, of which $62 \%$ contained peach cDNA inserts.

Identification of cDNA clones by dijferential hybridization. Cloned cDNAs representing mRNAs associated with fruit quality were isolated by differentially hybridizing the early 'Suncrest' cDNA library with radioactively labeled cDNA from 'Suncrest' and 'Bailey' fruit (30 DAB and $27 \mathrm{DAB}$, respectively). Ten clones that appeared to hybridize preferentially to 'Suncrest' cDNA and one clone (pch108) that appeared to hybridize preferentially to 'Bailey' cDNA were isolated from a screen of 2000 plaques from the amplified library. The cDNA inserts plus an additional 900 bases of vector DNA were separated from vector DNA by agarose gel electrophoresis following digestion with BamHI (The EcoRI cloning site is flanked by BamHI sites in the vector $\lambda$ :Zap.). Eight clones appeared to have identical-sized peach cDNA inserts following digestion with Barn HI. We further characterized only two of those, pch103 and pch115. Two other clones, pch102 and pch 106, were not further characterized because we were unable to detect an RNA transcript in northern blots that was related to the cDNA clones.

To identify cDNA clones representing mRNAs expressed differently between softening stages, 110,000 clones of the 'Loring' library were hybridized with cDNA synthesized from soft 'Loring' fruit RNA (4 to $19 \mathrm{~N}$ ) and with more firm 'Loring' fruit RNA (60 to $80 \mathrm{~N}$ ). Pch201 hybridized preferentially to the cDNA derived from the softer fruit, and pch202 hybridized preferentially to the cDNA derived from the firmer fruit.

To isolate genes expressed differentially between cultivars that have different texture characteristics, 110,000 clones were also screened with cDNA made from 'Suncling' fruit at their softest (20 to $39 \mathrm{~N}$ ) and cDNA made from the softest 'Loring' fruit (4 to 19 $\mathrm{N}$ ). One isolated clone, pch205, hybridized more strongly to the 'Loring' cDNAs than the 'Suncling' cDNAs.

pBluescript plasmids were isolated from the lambda clones pch103, pch108, pch115, pch201, pch202, and pch205 for further characterization (Table 1).

Oligonucleotide screening for specific cDNAs. We were interested in identifying peach cDNA clones representing

Table 1. cDNAs homologous to mRNAs accumulating during peach fruit development in 'Suncrest'.

\begin{tabular}{|c|c|c|c|c|c|c|}
\hline pch & $\begin{array}{c}\text { Library } \\
\text { source }\end{array}$ & $\begin{array}{c}\text { cDNA } \\
\text { insert size } \\
\text { (base pairs) }\end{array}$ & $\begin{array}{c}\text { mRNA } \\
\text { size } \\
\text { (bases) }\end{array}$ & $\begin{array}{c}\text { Detectable } \\
\text { in leaf }\end{array}$ & $\begin{array}{c}\text { Peak } \\
\text { expression }\end{array}$ & $\begin{array}{l}\text { Number } \\
\text { of genes }\end{array}$ \\
\hline 108 & Suncrest & 800 & 950 & +++ & Stage I & 1 to 5 \\
\hline 104 & Suncrest & 1200 & 1700 & + & Stage II & 10 to 50 \\
\hline 202 & Loring & 380 & 960 & + & Stage II & 1 to 5 \\
\hline 103 & Suncrest & 900 & 860 & t+ & Stage III & 1 to 5 \\
\hline 115 & Suncrest & 900 & 860 & ++ & Stage III & 1 to 5 \\
\hline 205 & Loring & 1350 & 1520 & ++ & Stage III & 1 to 5 \\
\hline 306 & 612615 & 2150 & $720,(1160)^{y}$ & ++ & Stage III & 1 to 5 \\
\hline 201 & Loring & 120 & 830 & - & Softening & 1 to 5 \\
\hline 307 & 612615 & 1650 & $1350,(2000)^{y}$ & + & Softening & 10 to 20 \\
\hline 313 & 612615 & 980 & $1420,(1700)^{y}$ & + & Softening & 1 to 5 \\
\hline
\end{tabular}

.The announts of detectable RNA were scored as follows: less than that found in fruit (-), the same as the lowest fruit (+), $30 \%$ of that found in maximum fruit $(++)$, and higher than that found in fruit $(+++)$.

y Number in parentheses represents the size of a second, less abundant transcript. 

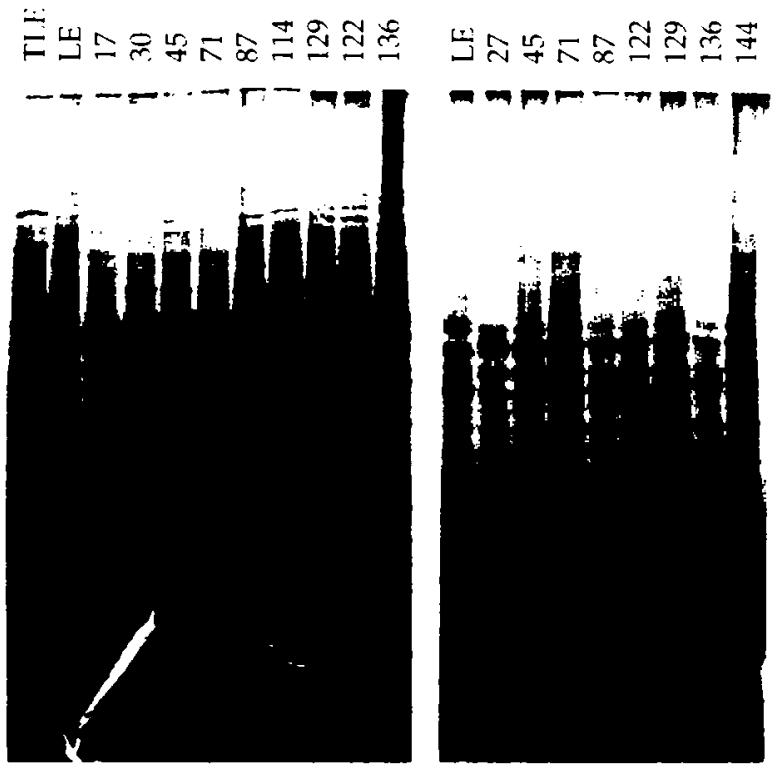

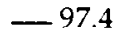

$-66.2$

$-42.6$

$-31$

Fig. 2. Autoradiograph of an in vitrotranslation of total RNAs from the commercialquality cultivar Suncrest and the rootstock-quality cultivar Bailey. Leaf RNA (LE), and fruit RNA from various days after bloom (top) from both cultivars were translated in a wheat germ translation system. 'Tomato leaf (TLE) RNA was used as a control RNA. Equal TCA precipitable counts were resolved on a $12 \%$ gel for sodium dodecyl sulfate-polyacrylamide gel electrophoresis and exposed to X-ray film for $36 \mathrm{~h}$. Molecular weight markers were resolved at the same time, and the position and sizes (in kilodaltons) are indicated to the right of the figure.

polygalacturonase, a wall-softening enzyme implicated in tomato fruit softening (Sheehy et al., 1988, Smith et al., 1988) and peroxidase, an enzyme potentially involved in a variety of phenomena such as lignification, flavor, color development, hormone degradation, etc. (Flurkey and Jen, 1978; van Huystee, 1987). To accomplish this, we synthesized oligonucleotides derived from tomato polygalacturonase and from a cucumber peroxidase sequence. Flurkey and Jen (1978) had reported a peak of peroxidase activity at $\approx 4$ to 6 weeks after bloom and a smaller peak at about the beginning of fruit ripening, i.e., Stage III. Six thousand clones of the 'Suncrest' early fruit library were screened with an 18-base mixed oligonucleotide probe to an ethylene-inducible cucumber peroxidase (Morgens et al., 1990). After a 32C wash, all the plaques exhibited equal hybridization signals. One plaque, pch 104, showed a preferential hybridization after a 37C wash, and no plaques gave a signal above background after a $42 \mathrm{C}$ wash. The ripe fruit libraries yielded no positive signals in 6000 B612615 clones or 8000 'Loring' clones.

A 44-mer oligonucleotide and a 39-mer oligonucleotide sequence were derived from a tomato cDNA sequence for polygalacturonase (Grierson et al., 1986). These were based on GC-rich regions rather than an active site or homologies with other polygalacturonases, because the information was not available. Accumulation of tomato polygalacturonase mRNA was reported to be associated with the climacteric period in fruit ripening (Grierson et al., 1985), so we screened the two ripe fruit libraries: 16,000 primary clones from the B612615 library and 24,000 clones from the amplified 'Loring' library. Two clones in the B612615 library, pch306 and pch307, hybridized preferentially
$\mathrm{DAB}$

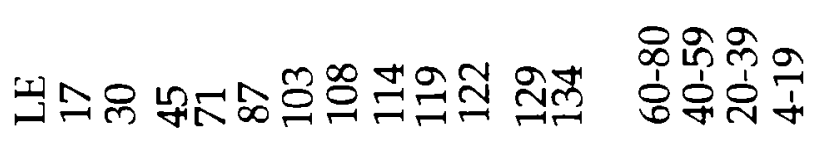

\section{FRUIT}

FIRMNESS (N) pch108

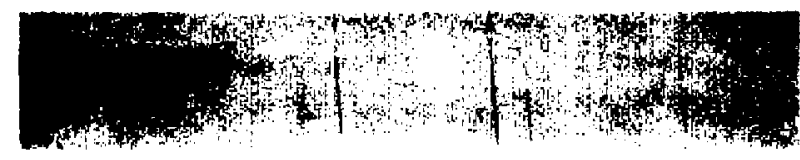

pch104

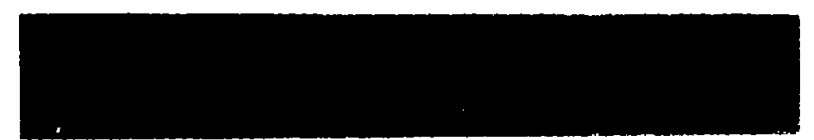

pch103
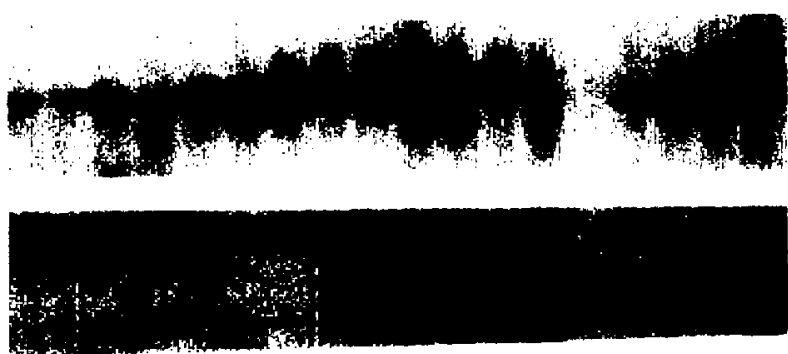

Stage II

Stage I

Stage III

Softening

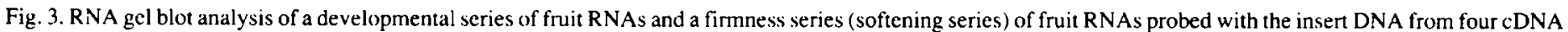

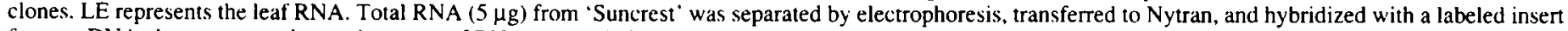
from a cDNA clone representing each pattem of RNA accumulation. 
after a $2 \times \mathrm{SSC}, 0.1 \%$ SDS, $37 \mathrm{C}$ wash. A clone that we believed to be random and that did not hybridize to the polygalacturonase oligonucleotides was isolated from a secondary screen as a ripe specific clone and designated pch313. No clones were recovered from the 'Loring' library in this screen.

Sibling analysis of cDNA clones. cDNA clones were crosshybridized in a sibling analysis to investigate their relatedness. Each plasmid (pch103, 104, 108, 115, 201, 202, 205, 306, 307, and 313) was digested, electrophoretically separated, and transferred to membranes for Southern blot analysis. Pchl03, 104, 115, 201, 202, 205, 307, and 313 plasmid DNAs were nick translated and each hybridized to a replica filter. Only pchl03 and pchl 15 crosshybridized with each other (data not shown). A Southern blot of EcoRI-digested DNA of pch306 and pch307 was hybridized with each polygalacturonase oligonucleotide. Pch306 hybridized with only the first oligonucleotide, and pch307 hybridized with only the second oligonucleotide (data not shown).

$m R N A$ expression. Peach fruit development in 'Suncrest' was monitored until $134 \mathrm{DAB}$ (overripe) and then divided into three stages according to fruit diameter (Fig. 1). Samples from which RNAs were extracted were chosen to represent at least two dates in each stage of development. Fruit began to soften by $100 \mathrm{DAB}$, so more dates were chosen in this period to overcome the fluctuations in results due to the unequal representation of softening at each of these time points. Fruit RNAs from this developmental series (17 to I34 DAB) and a softening series (4 to $80 \mathrm{~N}$ ) of 'Suncrest' were size fractionated along with a leaf RNA by gel electrophoresis, transferred to a membrane, and hybridized with various cDNAs. The mRNAs were divided into four categories as defined by the time of maximum accumulation during fruit development or softening (Fig. 3). One RNA gel blot was hybridized with a cDNA clone to the $25 \mathrm{~S}$ rRNA (Watson et al., 1987) to determine the evenness of loading. The loading is reasonably consistent with the softening series, having been somewhat overloaded. The experiments were repeated with new RNAs from the ' $a$ ' subset of the time points and at some other time points. The patterns of accumulation were the same, but certain time points had differences in relative amounts (data not shown). Most of these discrepancies could be attributed to a degraded RNA that was visible because the ribosomal RNA was also low.

The amount of pch108-related RNA decreased as the fruit developed (Fig. 4A), with the maximum accumulation in leaf tissue. The highest level detected in fruit was in immature fruit, 17 DAB. In late Stage III and in the softening series, there was little detectable pch 108 RNA.

Pch 104 and pch202 represent mRNAs that were most abundant in Stage II fruit at 71 DAB (Fig. 4B). The amount of these RNAs increase during Stage I and Stage II, while decreasing during Stage III. The accumulation level of both RNAs in the softening series was higher relative to the end of Stage III. Homologous RNAs were detectable in leaf tissue but at very low levels. The $>100 \%$ of maximum expression measured at 20 to $80 \mathrm{~N}$ using pch202 could be due to the fruit being collected in 2 years: i.e., the overall level of pch202-related RNA could have been higher in 1988 than in 1986 when the developmental series was collected. Numerous years of collecting would need to be done to test this idea.

mRNAs homologous with pch306 were present in leaves and increased in the fruit during development (Fig. 4C). A second, less abundant transcript was detected (1160 bases) and was accumulated in much the same pattern as the major transcript (data not shown).

Pch205 and pch 103, like pch306, detected mRNAs that accumulated throughout development, but mostly during Stage III (Fig.
A Constitutive and Stage I
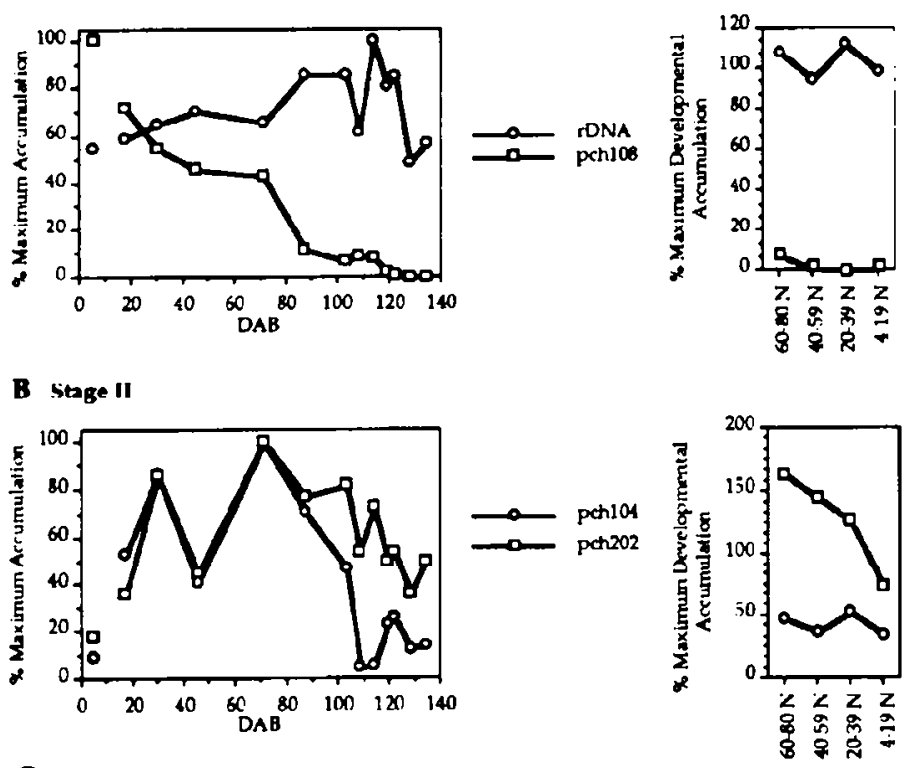

\section{C stage III}
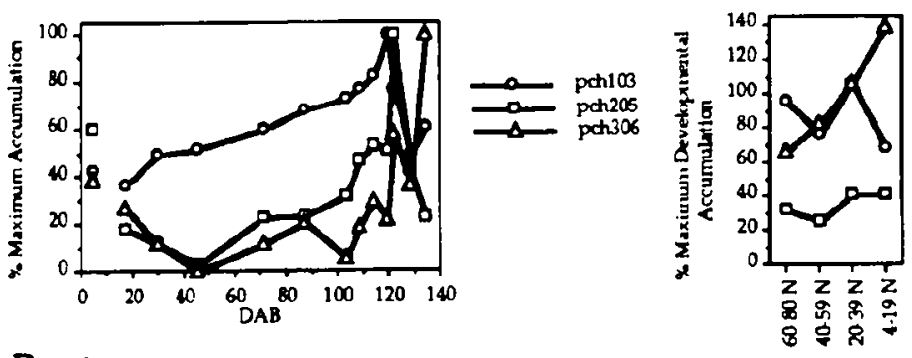

\section{Softening}
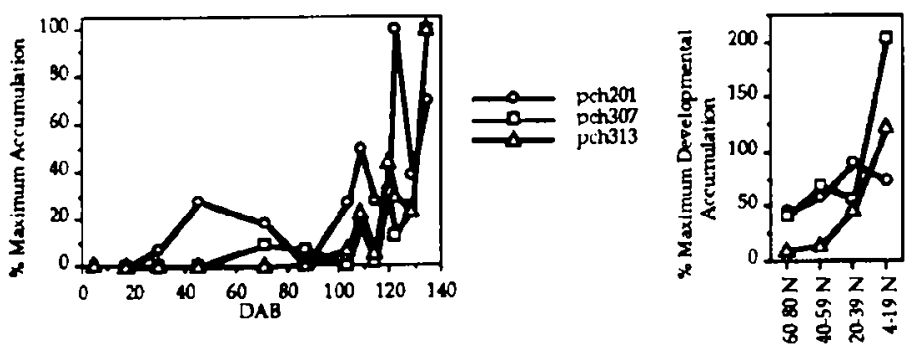

Fig. 4. The relative accumulation of specific mRNAs in 'Suncrest' fruit at various days after bloom (DAB) or during softening ( 4 to $80 \mathrm{~N}$ ). Leaf RNA is presented in the 5 DAB spot for comparison. The cpm bound at each time point were compared to the maximum cpm bound during the developmental series. The cpm bound in the softening series were also compared to the maximum cpm bound in the developmental series generating the values $>100$ or 0 in the case of pch 108 . This was done for comparison's sake only since the softening peaches were collected in a different year.

4C). Unlike pch306, maximum accumulation was detected before the fruit achieved their maximum size. This pattern is reiterated when examining the fruit firmness series. A decrease in the levels of pch205 mRNAs occurred during fruit softening to $\approx 40 \%$ of maximum levels. Pchl03 RNA accumulation also exhibited a decreased level during softening, but to a lesser extent.

Similar patterns of mRNA expression were seen with pch201, pch307, and pch313 (Fig. 4D). Less than 30\% of maximum accumulation was detected before $100 \mathrm{DAB}$. The major increase in levels of these RNA was detected during Stage III. The softening series indicates that there was between a 2- and 12-fold increase in the amount of related RNA detected between 60 and $80 \mathrm{~N}$ and 4 and 19 N. Pch307 and pch313 detected a second, less abundant 

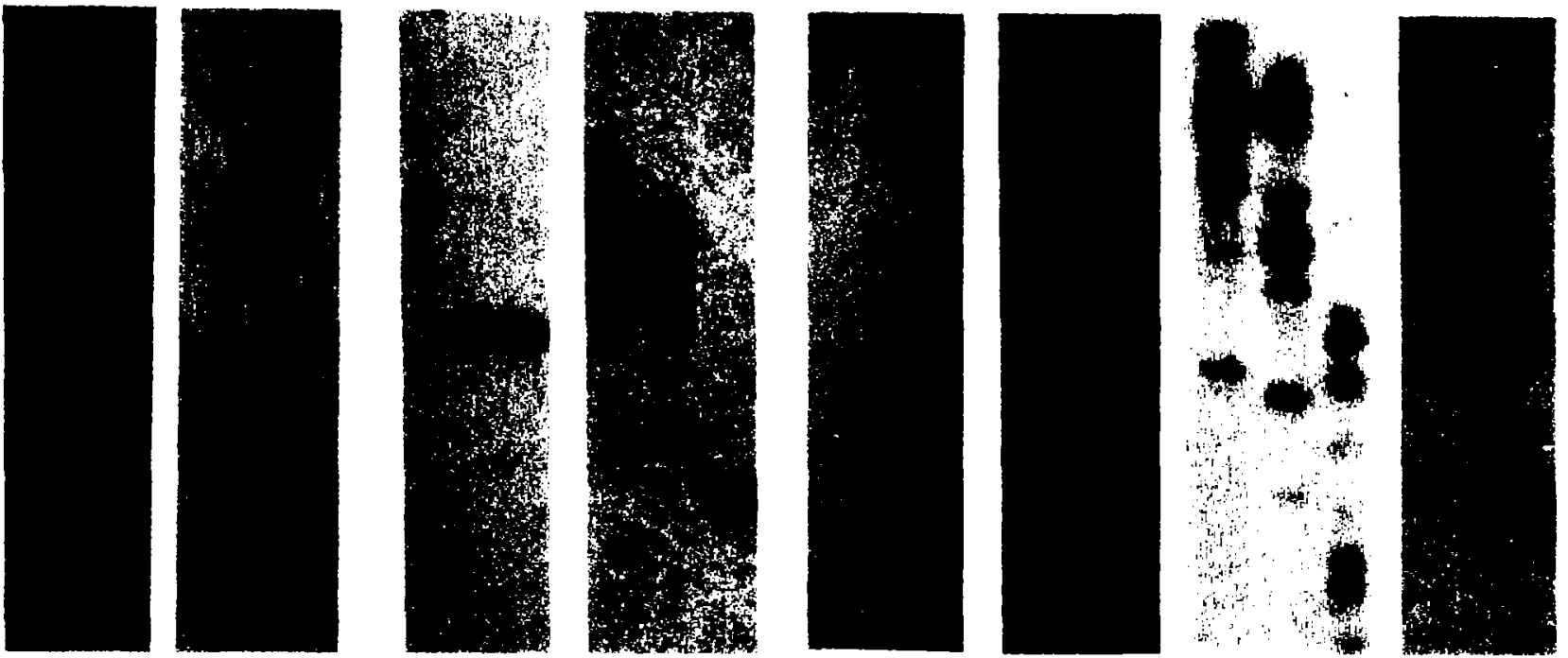

$->2$

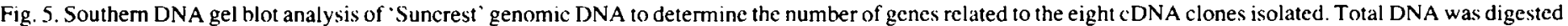
with BamHI (B), EcoRI (R), or HincII (H) and hybridized with the cDNA clone insert listed above the lanes. Lambda DNA was digested with PstI or EcoR V and resolved

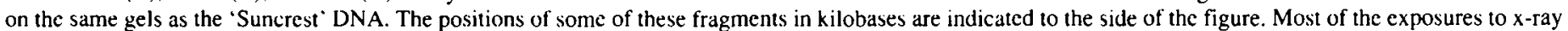
film were 2 to 3 days with two intensifying screens. Pchl(1) exposure was 2 h with screens.

transcript (2000 bases and 1700 bases, respectively), that accumulated in similar patterns as the predominant transcripts. No transcript is detected in leaves homologous to pch201, while transcripts can be detected after long exposures with pch307 and pch313.

Southern analysis. cDNAs were hybridized to 'Suncrest' genomic DNA gel blots to determine the number of related genes. All the cDNA clones hybridized, indicating complementary DNA sequences in the peach genome (Fig. 5). The signal derived from the pch201 Southern was too weak to reproduce, which is likely the result of the low specific activity of ${ }^{32} \mathrm{P}$ in the probe. Pchl03, 108, 201, 202, 205, 306, and 313 appear to be encoded by only one to five genes. Pch104 hybridized primarily to one fragment, but the intensity suggests it is a member of a small repetitive gene family. Numerous other fragments were detected at a lower signal, indicating that, in addition to the repetitive gene, there is a related family of genes (data not shown). Pch307 hybridized to numerous fragments, indicating a related family of genes.

In relation to the number of genes represented, four of our clones hybridized with more than one RNA transcript. Pch104 hybridized to one major RNA transcript and many minor ones, reflective of the pattern when hybridized to digested genomic DNA. Pch313 and pch307 hybridized to two RNA transcripts, equally reflective of the several genomic fragments potentially representing two related genes or two alleles. Pch306 detected two RNA transcripts yet has one major BamHI fragment and three EcoRI fragments. It also has two EcoRI sites within the insert, resulting in three fragments $\approx 600$ to 800 base pairs long. Pch306 may represent three cDNAs artificially linked together via cloning that have similar BamHI fragments, it may represent two cDNAs linked together via cloning that detect the two transcripts, or it may represent one cDNA with two internal EcoRI sites that detects two related transcripts.
Discussion

Nine cDNA clones, which represent genes whose mRNAs are developmentally regulated in relationship to the levels of large ribosomal RNA, have been isolated from peach. There are at least four patterns of regulation. One clone (pch 108) represents a gene that is expressed in leaves and decreases in fruit throughout development. Two clones (pch 104 and pch202) represent genes expressed primarily in Stage II of peach growth. Three clones (pch 103, pch205, and pch306) represent genes expressed primarily in Stage III of peach growth, and three clones (pch201, pch307, and pch313) represent genes expressed during the later part of Stage III, primarily during softening. The function of all but one of these genes is unknown.

The differential hybridizations were successful in that the clones isolated were differentially accumulated during fruit development. We isolated two clones representing genes with different amounts of RNA in early high-quality and rootstock-quality cultivars. Pch103 represents an abundant RNA, but its accumulation is primarily during Stage III. It came through the screen because it accumulates earlier in 'Suncrest' than in 'Bailey' fruit (data not shown). Pch108 is more abundant in 'Bailey' at this early stage but is very abundant in both cultivars in early fruit. Pch201, pch202, and pch205 represent genes whose RNA levels vary during the last stage of ripening and softening, either going up (pch201) or down (pch202 and pch205). which explains why they came through the screens. These patterns of RNA accumulation need to be correlated with fruit characteristics.

The clones isolated by homologies to known genes also represented RNAs regulated during fruit development We believe that clones pch306 and pch307, isolated by their homology to oligonucleotide sequences of tomato polygalacturonase, are not peach endopolygalacturonase. First, they do not hybridize with each 
other or with both oligonucleotides derived from tomato endopolygalacturonase. Second, the cDNA insert of pch307 has been partially sequenced and has no substantial sequence identity or similarity to tomato endopolygalacturonase (unpublished data). Third, a genomic clone for part of peach polygalacturonase has been sequenced and shares large regions of sequence identity with the tomato sequence (Lee et al.. 1990). One of the oligonucleotide sequences that we used is contained in the peach sequence and has very little similarity. Pch313, which was selected as a ripeningrelated clone in the polygalacturonase screens, has also been sequenced, and it appears to be a form of the ethylene-forming enzyme based on its sequence and expression patterns (Callahan et al., 1992)

We believe that pch104 is not a peroxidase gene. It also has been partially sequenced and does not have a high degree of sequence identity or similarity to known plant peroxidases. It does, however, have a high degree of sequence identity to the oligonucleotide sequences used to isolate the clone, and in fact has a small repetitive sequence that contains that homology (unpublished data). This may in fact be what is in common in the family of genes and transcripts detected with pch104 insert.

These genes can provide a base upon which to build knowledge of the genetic control of fruit development in peach. These clones can be used to assay for differences in expression during fruit development among cultivars with different fruit phenotypes. Expression patterns of these genes may then be correlated with fruit characteristics such as softening or texture. This could help to identify the role of these genes. In addition, these clones could be used in antisense constructions to determine the effects of varying the levels of these genes' end products on fruit development. This will require a peach transformation-regeneration system, and work is in progress (Hammerschlag et al., 1989; Scorza et al., 1990). Another potential application is using these clones as molecular markers (RFLPs) if they are associated with specific fruit characteristics. In this manner, these characteristics could be screened in the seedling stage rather than 3 years later, when the tree is mature enough to yield fruit. Three of these cDNAs have been found to be polymorphic among a wide range of commercial cultivars (Eldredge et al., 1992). Identifying the regulation elements in the genomic sequences of these cDNA clones could help elucidate the overall control of fruit development (Diekman and Fisher, 1988).

\section{Literature Cited}

Bailey, J.M. and N. Davidson. 1976. Methyl mercury as a reversible denaturing agent for agarose gel electrophoresis. Anal. Biochem. 70:75-85.

Biggs, MS., R.W. Harriman, and A.K. Handa. 1986. Changes in gene expression during tomato fruit ripening. Plant Physiol. 81:395-403.

Brooks, R.M. and H.P. Olmo. 1972. Register of new fruit and nut varieties. 2nd cd. Univ. of Calif. Press. Berkeley.

Callahan, A., P. Morgens, and E. Walton. 1989a. Isolation and in vitro translation of RNAs from developing peach fruit ( Prunus persica L. Batsch 'Reliance'). HortScience 24:356-358.

Callahan, A., P. Morgens, R. Scorza, S. Mante, J. Cordts, and R. Cohen. 1989b. Comparison of high and low quality peach fruit cultivars by differential hybridization of a cDNA library. Acta Hort. 254:48. (Abstr.)

Callahan, A., R. Scorza, P. Morgens, S. Mante, J. Cordts, and R. Cohen. 1991. Breeding for cold hardiness: Searching for genes to improve fruit quality in cold hardy peach germplasm. HortScience 26:522-526.

Callahan, A.M., P.H. Morgens, P. Wright, and K.E. Nichols, Jr. 1992. Comparison of pch313 (pTOM13 homolog) RNA accumulation during fruit softening and wounding of two phenotypically different peach cultivars. Plant Physiol. 100:482488.

Chalmers, D.J. and B. van den Ende. 1975. A reappraisal of the growth and development of peach fruit. Austral. J. Plant Physiol. 2:623-134.

Christoffersen, R.E., E. Warm, and G.G. Laties. 1982. Gene expression during fruit ripening in avocado. Planta 155:52-57.

Christoffersen, R.E., M.L. Tucker, and G.G. Laties. 1984. Cellulase gene expression in ripening avocado fruit: The accumulation of cellulase mRNA and protein as demonstrated by cDNA hybridization and immunodetection. Plant Mol. Biol. 3:385-391.

Connors, C.H. 1918. Growth of the fruit of the peach. N.J. Agr. Expt. Sta. Annu. Rpt. 40:82-88.

Diekman, J. and R.L. Fisher. 1988. Interaction of a DNA binding factor with the 5' flanking region of an ethylene-responsive fruit ripening gene from tomato. EMBO J. 7:3315-3320.

Eldredge, L., R. Ballard. W.V. Baird, A. Abbott, P. Morgens, A. Callahan, R. Scorza, and R. Monet. 1992. Application of RFLP analysis to genetic linkage mapping in peaches. HortScience 227:160-163.

Flurkey, W.H. and J.J. Jen. 1978. Peroxidase and polyphenol oxidase activities in developing peaches. J. Food Sci. 43: 1826-1831.

Giovannoni, J.J., D. DellaPenna, A.B. Bennett, and R.L. Fisher. 1989. Expression of a chimeric polygalacturonase gene in transgenic rin tomato fruits results in polyuronide degradation hut not fruit softening. Plant Cell 1:53-63.

Crierson. D., A. Slater, J. Speirs, and G.A. Tucker. 1985. The appearance of polygalacturonase mRNA in tomatoes: One of a series of changes in gene expression during development and ripening. Planta 163:263-271.

Grierson, D., G.A. Tucker, J. Keen, J. Ray, C.R. Bird, and W. Schuch. 1986. Sequencing and identification of a cDNA clone for tomato polygalacturonase. Nucleic Acids Res. 14:8595-8603.

Gubler, U. and G.J. Hoffman. 1983. A simple and very efficient way for generating cDNA libraries. Gene 25:263-269.

Hamilton, A.J., G.W. Lycett, and D. Grierson. 1990. Antisense gene that inhibits synthesis of the hormone ethylene in transgenic plants. Nature 346:284-287.

Hammerschlag, F.A., L.D. Owens, and A.C. Smigocki. 1989. Agrobacteriummediated transformation of peach cells derived from mature plants that were propagated in vitro. J. Amer. Soc. Hort. Sci. 114:508-510.

Herrin, D.L. and F.W. Schmidt. 1988. Rapid, reversible staining of northern blots prior to hybridization. BioTechniques 6:196-200.

Holdsworth, M.J., C.R. Bird, J. Ray, W. Schuch, and D. Grierson. 1987. Structure and expression of an ethylene related mRNA from tomato. Nucleic Acids Res. 15:731-739.

van Huystee, R.B. 1987. Some molecular aspects of plant peroxidase biosynthetic studies, p. 205-219. In: W.R. Briggs (ed.), Annual review of plant physiology. 38. Annu. Rev., Palo Alto, Calif.

Layne, R.E.C. 1982. Cold hardiness of peaches and nectarines following a test winter. Fruit Var. J. 36:90-98.

Lee, E., J. Speirs, J. Gray, and C.J. Brady. 1990. Homologies to the tomato endopolygalacturonase gene in the peach genome. Plant, Cell Environ. 13:513521

Lilien-Kipnis, H. and S. Lavee. 1971. Anatomical changes during the development of 'Ventura' peach fruits. J. Hort. Sci. 46:103-110.

Lincoln, J.E., S. Cordes, E. Read, and R.L. Fisher. 1987. Regulation of gene expression by ethylene during Lycopersicon esculentum (tomato) fruit development. Proc. Natl. Acad. Sci. United States 84:2793-2797.

Maniatis, T., E.F. Fritsch, and J. Sambrook. 1982. Molecular Cloning: A Laboratory Manual. Cold Spring Harbor Lab. Press, Cold Spring Harbor, N.Y.

Morgens, P.H., A.M. Callahan, L. Dunn, and F. Abeles, 1990. Isolation and sequencing of cDNA clones encoding ethylene-induced putative peroxidases from cucumber cotyledons. Plant Mol. Biol. 14:715-725.

Piechulla, B., K.R. Chonoles Imlay, and W. Gruissem. 1985. Plastid gene expression during fruit ripening in tomato. Plant Mol. Biol. 5:373-384.

Robertson, J.A., F.I. Meredith, and R. Scorza. 1989. Characteristics of fruit from high- and low-quality peach cultivars. HortScience 23:1032-1034.

Schuch, W., C.R. Bird, J. Ray. C.J.S. Smith. C.F. Watson, P.C. Morris, J.E. Gray, C. Arnold, G.B. Seymour, G.A. Tucker, and D. Grierson. 1989. Control and manipulation of gene expression during tomato ripening. Plant Mol. Biol. 13:303-313

Scorza, R., P.H. Morgens, S. Mante, J. Cordts, and A.M. Callahan. 1990 Agrobacterium -mediated transformation of peach ( Prunus persica L. Batsch) leaf segments, immature embryos, and long-term embryogenic calli. In Vitro Cellular Dev. Biol. 26:829-834.

Sheehy, R.E., M. Kramer, and W.R. Hiatt. 1988. Reduction of polygalacturonase activity in tomato fruit by antisense RNA. Proc. Natl. Acad. Sci. United States 85:8805-8809.

Smith, C.J.S., C.F. Watson. J. Ray, C.R. Bird, P.C. Morris, W. Schuch, and D. Grierson. 1988. Antisense RNA inhibition of polygalacturonase gene expression in transgenic tomatoes. Nature 334:724-726.

Tukey, H.B. 1933. Growth of the peach embryo in relation to growth of fruit and season of ripening. Proc. Amer.Soc. Hort. Sci. 30:209-218.

Watson, J.C., L.S. Kaufman, and W.F. Thompson. 1987. Developmental regulation of cytosine methylation in the nuclear ribosomal RNA gens of Pisum sativum. J. Mol. Biol. 193:15-26. 